\title{
NZSEE PRESIDENT'S PAGE
}

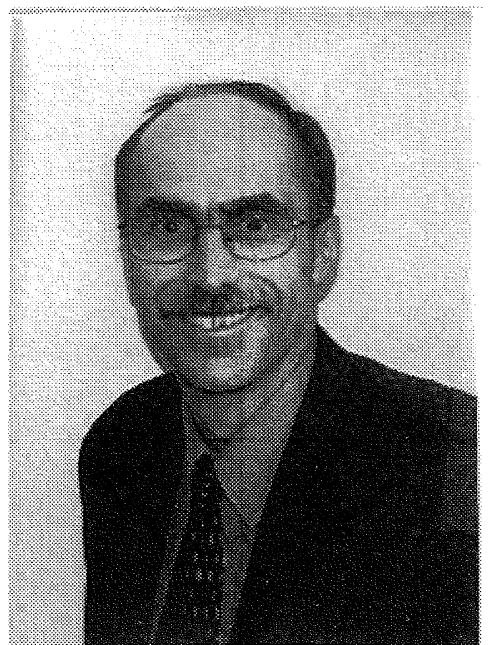

I am pleased to introduce myself as the Society's new President, having recently taken over the reins from Andrew King. It is an interesting time to look both back with satisfaction on the $12^{\text {th }}$ World Conference on Earthquake Engineering in Auckland and forward to the future direction of the Society.

\section{$12^{\text {th }}$ World Conference on Earthquake Engineering}

12 WCEE was a highly successful show, with very favourable international feedback. This is understood to have been the second biggest conference in terms of delegate numbers ever held in New Zealand! From the Society's 'bottom line' perspective, it is also very satisfying to report that a profit has been recorded.

The organisation of 12WCEE was a mammoth effort. I would like to convey on behalf of the Society sincere appreciation to the Organising Committee for their careful and comprehensive management of the conference. Special thanks are also due to the Technical Programme Committee for the huge task of structuring more than 2,700 abstracts into a workable 'batting order' - and having the flexibility to accommodate the two major earthquake events that occurred within six months of the conference!

\section{Members who served on these committees were:}

Bob Park, David Hopkins, Andrew King, Barry Davidson, Les Megget, Ian Billings, Arthur O'Leary, Euan Smith, Ivan Skinner, Jason Ingham, Kevin McManus, Ian Buckle, Michael Brice, Mick Pender, Warwick Smith, David Whittaker, Leicester Steven, Mike Beamish, Andrew Charleson and David Brunsdon.

Having surmounted the challenge of $12 \mathrm{WCEE}$ that has preoccupied senior members of the Society over the past four years, what lies ahead of us?

\section{Establishing Strategic Directions for the Society}

Many of the Society's activities have evolved in response to issues of the day, rather than as a result of a conscious forward planning process. At the instigation of Andrew King, a strategic planning workshop was held at the end of March involving more than 20 senior members of the Society and five invited guests to provide an external viewpoint. All aspects of the Society's activities were reviewed, and a wide range of ideas and options discussed. A number of key themes emerged, including:

- The Society needs to make more use of its strong reputation as a knowledgeable and independent body

- One of the key challenges we face is communicating our knowledge to the community and helping shape public perceptions of risk

- We need to actively seek the involvement of people from related fields in our activities, especially from the social sciences

- Our outputs (publications, study groups) need to be more focused on members' needs

A Strategic Plan which draws together the issues raised, and establishes the future strategic directions for the Society is currently being prepared. This represents the principal focus of the current Management Committee.

\section{Personal Reflections}

Working on this Strategic Plan has led me to reflect on a couple of occurrences that have had a strong influence on my involvement in the Society's activities.

The first was Bob Park inviting me to participate in the Society's study group on structures of limited ductility in 1985. At the tender age of 26 , I took this as a significant vote of confidence, and learned a great deal from working with the wise heads of that committee. Direct personal benefits included developing some enduring professional friendships. Also, the realisation that one could make a contribution in such company provided encouragement and motivation for future involvement.

It is apparent that the Society must more actively seek the involvement of younger engineers and scientists and people from other disciplines in both our technical and administrative activities.

The second was the 1989 Newcastle earthquake. I was fortunate to be involved for two years - starting the day after the event - working for the insurance industry, NSW Public Works Department and owners. This experience has shaped many of my attitudes towards earthquake mitigation and preparedness in New Zealand.

From a technical perspective, I observed first-hand the practical difficulties of carrying out building safety evaluations, along with the disruptive effect of the failure of utility services. Concern about the latter aspect has led to my subsequent involvement in Lifelines engineering. 
Perhaps the most telling aspect however was the complacent attitude of many (non-technical) New Zealanders - "at least we know all about earthquakes" that emerged at the time. Indeed as a nation we are well aware of the threat that earthquakes pose, but at the community level only a very small percentage of our population have experienced the effects and the aftermath of a damaging event.

This underlines the importance of the message that Society members must convey to the wider community. The task of sending this message in a constructive and balanced way is a real challenge.

The reconnaissance reports in this issue from last year's earthquakes in Turkey and Taiwan provide us with valuable information to use as "ammunition" for such a purpose. Please use these reports to brief colleagues, clients and others with - even if it is just the sections on Lessons for New Zealand.

Please let me know of the issues that you as a member of the Society are concerned about. I'd love to hear from you at drb@spencerholmes.co.nz

\section{David Brunsdon}

